\title{
A Respiratory-deficient Mutant in the Obligately Aerobic Yeast Hansenula wingei
}

\author{
By MARJORIE CRANDALL \\ Department of Microbiology, Indiana University, Bloomington, Indiana, 4740 I, U.S.A.
}

(Received 10 October 1972)

\begin{abstract}
SUMMARY
A glycerol-negative respiratory-deficient mutant is described which is not petite as judged by several criteria: (i) it grows slowly on glycerol; (ii) it reverts to glycerol-positive; (iii) it grows slowly on other non-fermentable carbon sources; and (iv) it has a normal cytochrome spectrum. It is not an oxidative phosphorylation mutant because the growth yield on glucose is the same as the parent. This $g l p$ mutant is specifically blocked in glycerol respiration but, in addition, is pleiotropic, affecting growth rates on other carbon sources, sporulation and diploid mitotic segregational frequencies of other genes.
\end{abstract}

\section{INTRODUCTION}

Because Hansenula wingei lacks the ability to ferment (Wickerham, I970), all substrates are oxidized aerobically via the chain of respiratory enzymes. Crandall (1973) found that the cytoplasmic respiratory mutation called petite (Slonimski, I949; 1953) cannot be isolated in $H$. wingei. Any other type of respiratory-deficient mutation resulting in complete loss of respiratory activity should also be lethal. Results of ultraviolet mutagenesis were in agreement with this hypothesis since the only respiratory-deficient mutant obtained after extensive irradiation contained partial activity. This mutant, $2 I$ ade $g l p$, was isolated by screening for mutants which could grow on glucose but not on glycerol (Crandall, I973). The results presented here demonstrate that this glycerol-negative mutant is not a petite nor is it an oxidative phosphorylation mutant. Respiration of glycerol is specifically blocked in this mutant but the nature of this specific block is not known.

\section{METHODS}

Media, cultural conditions, yeast strains, etc. Same as for Crandall (1973).

Cytochrome spectra. The method of Claisse, Pere-Aubert, Clavilier \& Slonimski ( 1970) was employed to measure absorption due to reduced cytochromes in yeast cakes at liquid nitrogen temperatures. Cells were scraped off plates, dried between filter papers, transferred to cuvettes, mixed with a pinch of sodium dithionite and smoothed to fill the cavity. The cuvette was covered and pre-equilibrated in liquid nitrogen before taking the spectrum.

Respiratory $Q_{\mathrm{O}_{2}}$. Oxygen uptake by washed cell suspensions was measured with a platinum oxygen electrode using the method of Somlo ( 1968 ). To a $2.0 \mathrm{ml}$ platinum electrode cell was added: $\mathrm{I} \cdot 7 \mathrm{ml}$ of $50 \mathrm{~mm}-\mathrm{K}$ phthalate buffer, $\mathrm{pH} 4.0$ at $30^{\circ} \mathrm{C}$., $0.1 \mathrm{ml}$ cell suspension in water; and $50 \mu \mathrm{l}$ of $5 \%$ ethanol, $40 \%$ glucose or $20 \%$ glycerol. Sodium azide $\left(\mathrm{NaN}_{3}\right)$ was added to a final concentration of $3 \mathrm{~mm}$. Protein was measured by the biuret method for whole cells (Stickland, I95I). 


\section{RESULTS}

Isolation of a glycerol-negative mutant 21 ade glp. Strain 21 ade was irradiated with ultraviolet light (as described in Crandall, 1973). After phenotypic expression in glucose broth, mutagenized cells were plated on glucose. This glycerol-negative mutant was unable to grow on glycerol plates after replica plating from glucose. During streak purification, the original isolate segregated out small colonies on glucose. A large subclone was picked at each single colony isolation until it bred true.

Comparison of growth rates of parent and glycerol-negative mutant. Strain 21 ade glp has a specific impairment in growth on glycerol (Fig. I) but, in addition, it grows at a slightly reduced rate on glucose (Fig. 2). Growth rates on glycerol, ethanol and lactate are reduced by about the same relative amount as compared to the parent $(2 \cdot 4,2 \cdot 0,2 \cdot 5$ respectively). The glycerol-negative phenotype on plates is quite definitive; colonies on glucose plates are smaller than the parent but colonies appear on glycerol plates only after a lag of several days. Replica plating from glucose to glycerol results in the clearest distinction, there being no growth at all of the $g l p$ mutant even after 2 days, whereas the parent gives heavy growth after I day. Previous growth on glucose appears to delay cell division of this mutant on glycerol (Fig. I) explaining the definitive glycerol-negative phenotype upon replica plating.

Reversion to glycerol-positive. If cells of 21 ade glp are plated at high cell density on glycerol plates, fast growing revertant colonies will appear after about a week at a frequency of about $10^{-7}$.

Cytochrome spectra. Comparison of the cytochrome content in the parent and the mutant revealed no major differences (Fig. 3). Even though the cells were grown on glucose, both spectra were similar to the cytochrome spectrum obtained with derepressed cells of Saccharomyces cerevisiae (Claisse, Pere-Aubert \& Clavilier, 1970).

Comparison of growth yield on glucose of parent and glycerol-negative mutant. No differences in terminal extinctions were obtained when cells were grown on low glucose concentrations (0.0 I to $0.10 \%)$. This means that the mutant utilized glucose as efficiently as the parent. However, $2 I$ ade glp did take longer to reach the same terminal extinction especially at higher than $0.1 \%$ glucose concentrations. This confirms the observation (Fig. 2) that the mutant grows more slowly on glucose. It can therefore be concluded that this mutant is only partially defective in respiratory activity.

Reduction of glycerol-specific respiration. The specific reduction in growth ability of $2 I$ ade $g l p$ on glycerol (Fig. I) is correlated with a specific reduction in glycerol respiration (Table I). Exponential cultures of both parent and mutant in glucose broth were used for measurement of oxygen uptake instead of stationary cultures because older cultures had decreased respiration rates. Starvation decreased endogenous and total respiration in both strains. Sodium azide completely inhibited respiration of glucose or glycerol in both strains. Ethanol gave the greatest stimulation of respiration in both strains and therefore these respiratory $Q_{0_{2}}$ values were set equal to $100 \%$. Glucose and glycerol were equally less efficient than ethanol in stimulating respiration in the parent. In contrast, the glycerolnegative mutant respired glycerol at a decreased rate as compared to glucose. The relative decrease in respiration of glycerol compared to glucose $(2 \cdot 0)$ is similar to the relative decrease in growth rate on glycerol as compared to glucose $(2 \cdot 4)$. In summary then, the defect in this glycerol-negative mutant is only partial, affects all carbon sources but glycerol utilization in particular.

Meiotic and mitotic segregation. Mutant $2 I$ ade glp did not sporulate in a cross with 


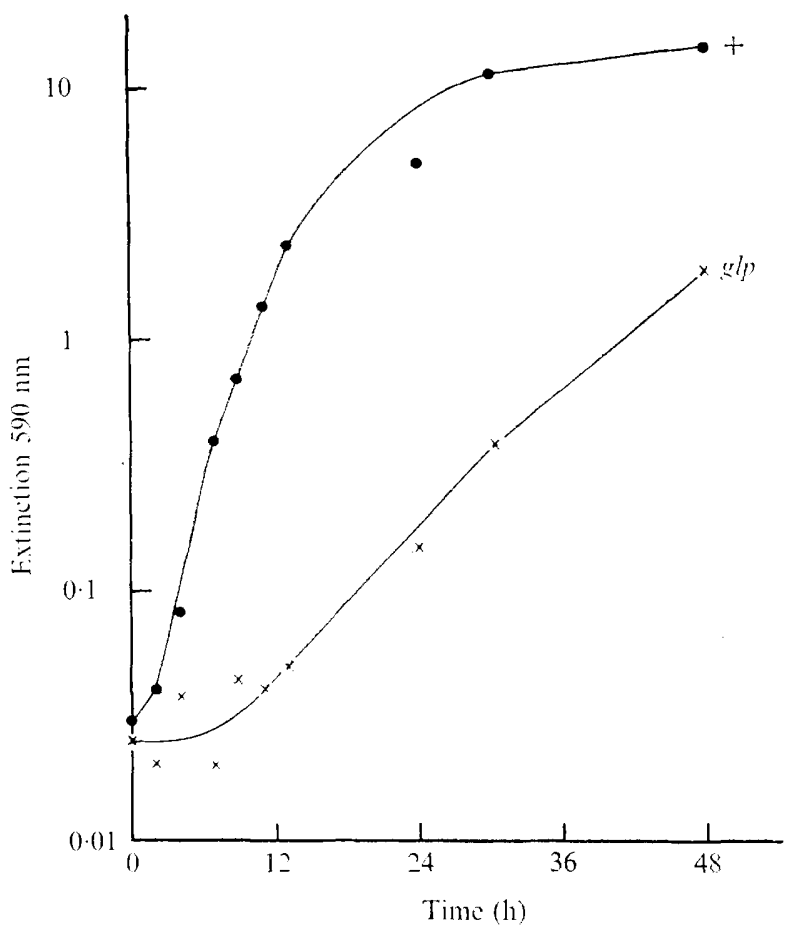

Fig. I. Growth of parent and glycerol-negative mutant on glycerol. Cells of Hansenula wingei strain $2 I$ ade and mutant $2 I$ ade glp were grown overnight to stationary phase in YG broth (0.7\% yeast extract (Difco), $3 \%$ glucose and $0.5 \% \mathrm{KH}_{2} \mathrm{PO}_{4}$, harvested, resuspended in saline and diluted about $\mathrm{I} / \mathrm{IOO}$ into $\mathrm{YG}$ broth so that the initial extinction at $590 \mathrm{~nm}$ was about 0.02 in a 'Spectronic 20 ' spectrophotometer (Bausch \& Lomb, Rochester, New York, U.S.A.). Samples of culture and broth were diluted in saline above an extinction reading of 0.6 .

\section{Table 1. Reduction of glycerol-specific respiration in a glycerol-negative mutant}

Cells were grown from a low inoculum to exponential phase in natural broth with good aeration (200 $\mathrm{ml} / \mathrm{l}$ Erlenmeyer on a reciprocal shaker). Cells were harvested, washed in $\mathrm{H}_{2} \mathrm{O}$, resuspended in $\mathrm{H}_{2} \mathrm{O}$ at $\times \mathrm{I}$, starved for $3.5 \mathrm{~h}$, harvested and resuspended in water at $\times 25$. Endogenous oxygen uptake by the cell suspension equilibrated at $30^{\circ} \mathrm{C}$ was measured, then substrate was added and the total rates were measured. Values for the total respiratory $Q_{\mathrm{O}_{2}}$ are calculated relative to ethanol taken as $100 \%$. The parental $Q_{\mathrm{O}_{2}}$ with ethanol was $159 \mathrm{~nm}^{2} / \mathrm{h}$. mg protein and the average parental endogenous $Q_{\mathrm{O}_{2}}$ was 48 . The mutant $Q_{\mathrm{O}_{2}}$ with ethanol was 102 and the average mutant endogenous $Q_{\mathrm{O}_{2}}$ was 3 I.

$\begin{array}{cc}\text { Parent } & \text { Mutant } \\ 2 I \text { ade } & \text { 2I ade glp } \\ \text { I.00 } & \text { I } .00 \\ 0.79 & 0.66 \\ 0.84 & 0.33\end{array}$

Hansenula wingei VIB tester (see description of strains in Crandall, 1973), even though the parent $2 I$ ade did sporulate in the hybrid with VIB. This prevented tetrad analysis. The mutant did, however, segregate one glycerol-negative diploid out of about $10^{4}$ heterozygous $g l p /^{+}$- diploids tested which is a typical frequency for nuclear mitotic segregation and low for mitochondrial segregation. This glycerol-negative diploid segregant was also 


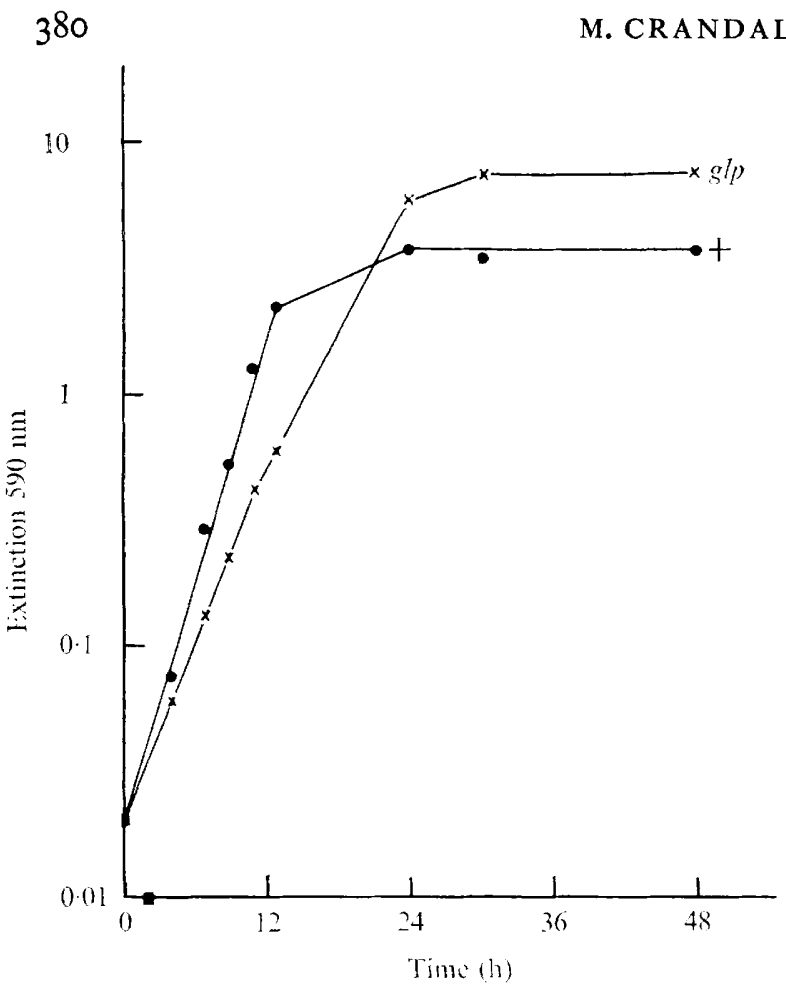

Fig. 2

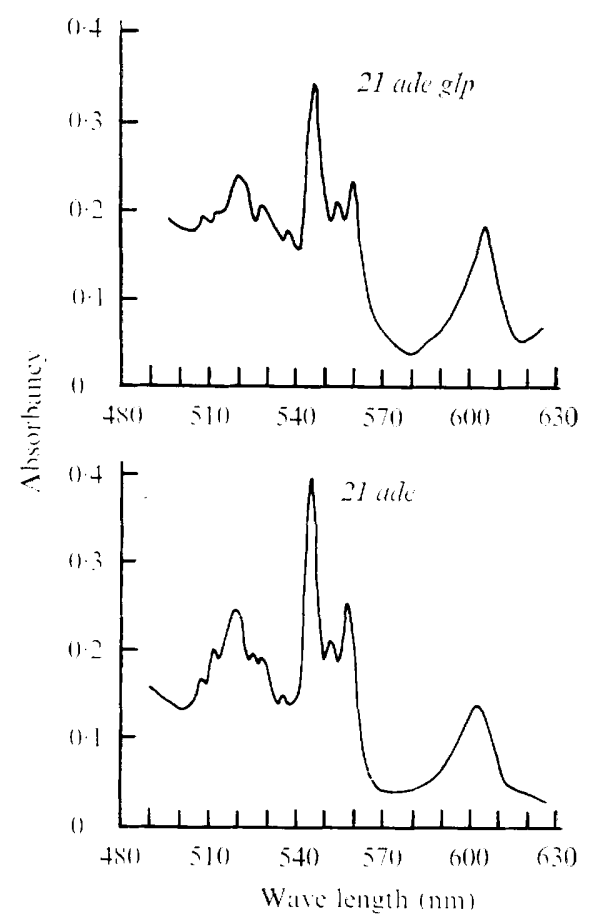

Fig. 3

Fig. 2. Growth of parent and glycerol-negative mutant on glucose. Cells of Hansenula wingei strain $2 I$ ade and mutant $2 I$ ade glp were grown overnight to stationary phase in YG broth, harvested, resuspended in saline and diluted about $\mathrm{I} / \mathrm{I} 00$ into Ygly broth $(0.7 \%$ yeast extract (Difco), $3 \%$ glycerol and $0.5 \% \mathrm{KH}_{2} \mathrm{PO}_{4}$ ). The rest of the procedure was identical to Fig. I.

Fig. 3. Cytochrome spectra of parent and glycerol-negative mutant. Cells from a glucose broth preculture $(0.5 \mathrm{ml})$ were spread on glucose plates and incubated 2 days. The plates were refrigerated until use.

asporgenic as was the $\left.g l p\right|^{+}$-hybrid. This glyceral-negative segregant from the hybrid 5 cyh lys etb-36 $\times 21$ ade glp was also ethidium bromide (EB) sensitive which suggests linkage between $g l p$ and the nuclear gene for EB sensitivity (Crandall \& Richter, to be published).

\section{DISCUSSION}

The glycerol-negative mutant described in this paper is not a petite and is not an oxidative phosphorylation mutant of the phenotype predicted in Somlo (197I). Respiration of glycerol is particularly reduced in this mutant. There was a marked consistency in the reduction in the growth rates on glycerol, ethanol and lactate indicating the involvement of a common element which is important in the oxidation of all these non-fermentable substrates but which is more important for glycerol respiration. Since this mutant prevents sporulation in the heterozygous state it can be considered semidominant. Since glycerol metabolism occurs in the cytoplasm (Gancedo, Gancedo \& Sols, 1968) the $g l p$ gene is probably nuclear. The mitotic segregational frequency of glycerol-negative diploids from the $g l p /^{+}$diploid is about $10^{-4}$ consistent with $g l p$ being a nuclear mutation as is the mitotic segregation of the $g l p$ gene with a marker for EB sensitivity. This glycerol-negative mutant also affects the diploid mitotic segregational frequencies of an EB resistance marker in the heterozygous 
diploid (Crandall \& Richter, to be published). Other mutants have been described which affect diploid mitotic segregational frequencies of unrelated genes and which also do not sporulate (Mori \& Nakai, I968; Resnick, 1969). These mutants are presumably involved in DNA repair. The $g l p$ mutant described here is obviously pleiotropic in its action, affecting nuclear as well as cytoplasmic events.

Special thanks are extended to Dr Marika Somlo for making the measurement of cellular respiration possible. Assistance provided by Mrs Joan Caulton and Mrs Rudina Richter in some experiments is acknowledged. Professor A. Linnane is thanked for suggesting the experiment on growth yield. This investigation was performed while M.C. was a postdoctoral fellow of the newly established exchange fellowship programme between the U.S. National Science Foundation and the French Centre National de la Recherche Scientifique, and was supported by a grant from the Délégation Générale à la Recherche Scientifique et Technique, Comité de Biologie Moléculaire. The paper was written while M.C. was supported by U.S.P.H.S. Grant GM I 8708.

\section{REFERENCES}

Claisse, M. L., Pere-Aubert, G. A., Clavilier, L. P. \& Slonimsky, P. P. (1970). Methode d'estimation de la concentration des cytochromes dans les cellules entieres de levure. European Journal of Biochemistry 16, 430-438.

Crandall, M. (1973). Comparison of Hansenula wingei, a petite-negative, obligately aerobic yeast, to the petite-positive yeast Saccharomyces cerevisiae. Journal of General Microbiology 75, 365-375.

Gancedo, C., Gancedo, J. M. \& Sols, A. (I968). Glycerol metabolism in yeasts. European Journal of Biochemistry 5, 165-172.

MORI, S. \& NAKAI, S. (I968). Induction of allelic recombination in UV and X-ray sensitive mutants of yeast. Proceedings of the XII International Congress of Genetics $\mathbf{x}, 80$.

RESNICK, M. A. (1969). Genetic control of radiation sensitivity in Saccharomyces cerevisiae. Genetics 62 , 519-531.

Slonimski, P. P. (1949) Action de l'acriflavine sur les levures. IV. Model d'utilisation du glucose par les mutants 'petite colonies'. Annals de l'Institut Pasteur 76, 510-530.

Slonimski, P. P. (1953). Formation des enzymes respiratoires chez le levure. Paris: Masson.

SomLo, M. (1968). Induction and repression of mitochondrial ATPase in yeast. European Journal of Biochemistry 5, 276-284.

SomLo, M. (I971). Oxidative phosphorylation in intact cells of normal and op mutant yeast undergoing respiratory adaptation. Biochimie $\mathbf{5 3}, 819-830$.

STICKLAND, L. H. (I95I). The determination of small quantities of bacteria by means of the biuret reaction. Journal of General Microbiology 5, 698-703.

Wickerham, L. J. (1970). Hansenula H. et P. Sydow. In The Yeasts: A Taxonomic Study, pp. $226-315$. Edited by J. Lodder. Amsterdam: North Holland Publishing Co. 